\title{
Rancang Bangun Kendali Suhu Pemanas Tangki Berpengaduk Kontinyu menggunakan Pengendali PID berbasis NI ELVIS II dan LabVIEW
}

\author{
Imam Febiawan ${ }^{1}$, Noval Lilansa ${ }^{2}$, Abyanuddin Salam ${ }^{3}$ \\ ${ }_{1,2,3}$ Politeknik Manufaktur Bandung, Indonesia \\ ${ }^{1}$ imam.febiawan@mhs.polman-bandung.ac.id* \\ * corresponding author
}

\begin{abstract}
This paper proposes a temperature control system on a continuous stirred tank heater prototype using a PID controller. Input value parameters and system responses are displayed on a GUI (Graphical User Interface) connected to a computer (PC or Laptop) so that they can be monitored in real-time. The sensor used in the stirred tank heater consists of two LM35DZ temperature sensors. The results of the temperature sensor readings are entered into the data acquisition device (NI ELVIS II) as a data processing process which is then processed using LabVIEW and displayed on the GUI. The results of this study can provide a model of a continuous stirred tank heater temperature control system with a water room temperature range up to $45^{\circ} \mathrm{C}$ using the parameters $\mathrm{PI} \mathrm{Kp}=83.2 \mathrm{Ti}$ $=0.03, T d=0$.
\end{abstract}

Article Info

\footnotetext{
ABSTRAK

Paper ini mengusulkan sebuah sistem kendali suhu pada sebuah prototipe pemanas tangki berpengaduk kontinyu menggunakan pengendali PID. Parameter nilai masukan dan respon sistem ditampilkan pada GUI (graphical user interface) yang terhubung dengan komputer (PC atau Laptop) sehingga dapat dipantau secara waktu riil. Sensor yang digunakan pada alat pemanas tangki berpengaduk terdiri dari dua buah sensor suhu LM35DZ. Hasil pembacaan sensor suhu tersebut dimasukkan pada perangkat akusisi data (NI ELVIS II) sebagai proses pengolahan data yang selanjutnya diolah menggunakan LabVIEW dan ditampilkan pada GUI. Hasil penelitian ini mampu memberikan sebuah model sistem kendali suhu pemanas tangki berpengaduk kontinyu dengan rentang suhu

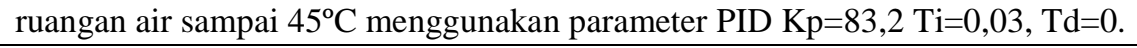

\section{PENDAHULUAN}

Pemanas memiliki peran penting dalam proses industri, terutama industri kimia dan industri produk minuman, yaitu untuk meningkatkan efisiensi proses dan menghasilkan kualitas produk yang baik. Salah satu jenis pemanas di industri kimia yang banyak digunakan adalah pemanas tangki berpengaduk. Pemanas tangki berpengaduk terdiri dari beberapa bagian, salah satunya adalah elemen pemanas yang digunakan sebagai pemanas untuk mengubah bahan baku menjadi produk yang lebih bernilai guna. Masalah yang sering dihadapi dalam proses tersebut adalah keakuratan suhu pada tangki pemanas. Agar suhu tangki tersebut mencapai titik setel dengan kecepatan respon dan akurasi yang tinggi, maka diperlukan sebuah pengendali (Septiani et al., 2017). 
Salah satu penerapan pengendalian suhu yang digunakan adalah metode untuk menentukan parameter pengontrol Proportional Integral Derivative (PID) menggunakan metode algoritma genetika dengan pengontrol Fuzzy Logic Stirred Tank Heater. Perancangan sistem Fuzzy Logic digunakan untuk mencari parameter dalam Algoritma Genetika yaitu probabilitas crossover dan probabilitas mutasi. Parameter ini digunakan untuk mencari nilai $\mathrm{Kp}, \mathrm{Ki}$, dan $\mathrm{Kd}$ pada kontroler PID (Septiani et al., 2017). Penelitian selanjutnya menyajikan analisis perbandingan kinerja pengendali PID dan pengendali Fuzzy PID untuk kontrol proses CSTH (Continuous Stirred Tank Heater) (Kabila \& Glan Devadhas, 2015).

Penelitian lain menjelaskan mengenai perbandingan konfigurasi pengendali cascade dan feedforward-feedback dalam menjaga dan mengatur suhu di Stirred Tank Heater (Yudho Suprapto et al., 2018). Begitupun penelitian selanjutnya memaparkan perbandingan dua pengendali dalam pemodelan kendali suhu pemanas tangki berpengaduk. Analisis sistem loop terbuka menunjukkan bahwa sistem tidak efisien tanpa pengendali. Pengendali Linear Quadratic Gaussian (LQG) dan Linear Quadratic Integral (LQI) digunakan untuk meningkatkan kinerja sistem. Perbandingan sistem loop tertutup dengan pengontrol yang diusulkan dilakukan dengan Matlab / Simulink Toolbox (Jibril et al., 2020).

Penelitian yang lain memaparkan penerapan tiga pengendali berbeda pada proses kimia seperti pemanas tangki berpengaduk. Tiga pengendali yang digunakan adalah PID, PID berbasis IMC (Internal model controller), dan pengendali adaptif gain scheduling. Sebuah studi simulasi dilakukan dengan menggunakan MATLAB untuk mengontrol sistem proses menggunakan pengendali yang disebutkan di atas. Dengan bantuan studi simulasi dan kriteria kinerja integral waktu, penelitian ini dapat menyimpulkan kontroler mana yang paling cocok untuk sistem pemanas tangki berpengaduk (Rajagopalen, 2013). Penyetelan parameter PID dapat diusulkan dengan pengendali PID berbasis genetic algorithm (GA) yang dioptimalkan dalam proses continuous stirred tank reactor (CSTR) menggunakan kombinasi fungsi tujuan yang berbobot yaitu, integral square error (ISE), integral absolute error (IAE), dan integrated time absolute error (ITAE). Parameter PID yang dioptimalkan secara global cenderung mengoperasikan proses CSTR di seluruh rentang operasi untuk mengatasi keterbatasan pengontrol PID linier (Jayachitra \& Vinodha, 2014).

Penelitian-penelitian terdahulu berfokus pada hasil akhir yang dituju, yaitu berhasil mengendalikan suhu pemanas tangki berpengaduk kontinyu dan menampilkan grafik respon suhu fluida yang dipanaskan. Jenis-jenis pengendalian yang telah digunakan untuk sistem ini diantaranya pengendali PID berbasis algoritma genetika, PID berbasis internal model controller (IMC), pengendali adaptif gain scheduling, Pengontrol Linear Quadratic Gaussian ( $L Q G$ ), pengontrol Linear Quadratic Integral (LQI), Cascade controller, Feedforward-Feedback Controller, pengendali PID Fuzzy, pengendali PID dengan algoritma genetika ditambah logika fuzzy, dan pengendali PID konvensional atau klasik. Penelitian yang sudah dilakukan menggunakan metode pengendalian yang kompleks dalam penerapan pada sistem pemanas tangki berpengaduk. Mayoritas pengendali yang digunakan pada pembahasan diatas adalah pengembangan dari PID konvensional, sehingga pengendali PID konvensional merupakan dasar dari penerapan sistem kendali yang ada pada saat ini. Maka dari itu, sistem pengendalian yang digunakan pada penelitian ini adalah pengendali PID konvensional. Selain itu, Pengendali PID konvensional merupakan salah satu jenis pengendali yang paling banyak digunakan $90 \%$ industri karena skema kendali lanjutan yang sederhana, fungsionalitas yang jelas, kemudahan penerapan dan penggunaan yang disediakan oleh sistem kendali ini, sehingga pengguna dapat memiliki pengalaman dalam menyetel parameter PID walaupun tidak secara 
langsung di industri (Jayachitra \& Vinodha, 2014).

Sistem pengendalian pada penelitian ini mengatur suhu fluida dalam pemanas tangki berpengaduk kontinyu menggunakan sensor LM35DZ sebagai pendeteksi suhu. Kemudian, prototipe ini memiliki tiga buah aktuator dengan fungsinya masing-masing, yaitu elemen pemanas untuk menaikkan suhu dalam tangki, pompa air untuk memasukkan air yang akan dipanaskan dengan kecepatan aliran konstan dan mengeluarkan air dari proses pemanasan dalam tangki, serta motor pengaduk untuk mencampurkan suhu air yang berasal dari suhu air masukkan dan elemen pemanas sehingga suhu air dalam tangki homogen. Sistem pengendalian ini memilki sistem antarmuka berbasis GUI (graphical user interface) yang dapat menampilkan data-data masukkan dan keluaran sistem melalui komputer (PC atau Laptop) menggunakan aplikasi LabVIEW serta perangkat akusisi data NI ELVIS II+.

\section{METODE}

Penelitian ini terbagi atas tiga bagian utama diantaranya, perancangan perangkat keras pemanas tangki berpengaduk kontinyu, perancangan elektrik NI ELVIS II, dan perancangan perangkat lunak pada LabVIEW.

Model sistem pemanas tangki berpengaduk ini dirancang untuk memanaskan air dalam tangki proses. Perangkat mekanik pada model pemanas tangki berpengaduk terdiri dari tiga buah tangki, baling-baling, selang, saluran masuk dan saluran keluar air. Tangki proses didesain dengan diameter dalam $11 \mathrm{~cm}$, ketebalan tangki $0,3 \mathrm{~cm}$ dan tinggi tangki 21,7 cm dari dasar bagian dalam tangki. Berdasarkan ukuran tangki yang sudah diketahui, volume air dalam tangki ingin dipertahankan sebesar 1000 mL. untuk mencapai hal tersebut, posisi ketinggian dari saluran masuk dan saluran keluar harus diperhitungkan. Hasil perhitungan menggunakan rumus volume tabung, ketinggian posisi saluran masuk dan saluran keluar yaitu $10,5 \mathrm{~cm}$ dari dasar tangki bagian dalam.
Dibawah posisi saluran masuk dan saluran keluar, terdapat sensor yang dipasang dan saling berhadapan. Posisi sensor tersebut ditujukan agar pembacaan suhu dalam tangki sudah tercampur merata disetiap sisinya antara suhu yang dipanaskan oleh elemen pemanas di bagian bawah tangki dan suhu air yang masuk di bagian atas tangki. Selain itu, baling-baling ditempatkan di bagian tengah tangki dengan tujuan untuk meratakan suhu dalam tangki yang digerakkan oleh motor DC.

Model pemanas tangki berpengaduk menggunakan tiga tangki yaitu tangki cairan, tangki proses, dan tangki penampung. Tangki cairan berisi fluida air yang akan diproses pada tangki proses. Air dipindahkan dari tangki cairan ke tangki proses menggunakan pompa air. Pompa akan terus mengisi tangki proses dan air keluar ke tangki penampung. Pompa air ditempatkan pada dasar yang sama dengan tangki. Pompa tersebut dihubungkan menggunakan selang berukuran 5/16 inci. Proses pemindahan air dari tangki proses ke tangki penampung menggunakan sifat air yang selalu berpindah ke daerah yang lebih rendah, gaya gravitasi bumi, dan didorong oleh aliran air yang masuk ke tangki proses.

Perancangan elektrik pemanas tangki berpengaduk kontinyu berpusat pada papan prototipe NI ELVIS II. Papan prototipe ini menjadi tempat terhubungnya sensor-sensor dan penggerak aktuator dengan perangkat akusisi data. Koneksi rangkaian papan prototipe sistem pemanas tangki berpengaduk dibuat secara modular agar lebih mudah dipahami dan dibaca. Koneksi pin papan prototipe terdiri dari sambungan sensor suhu ke-1 dan ke-2, penggerak elemen pemanas, penggerak motor pengaduk, dan penggerak pompa air.

Terdapat dua buah sensor suhu. Konektor sensor suhu terdiri tiga pin, dua pin untuk catu daya, dan satu pin untuk data. Catu daya kedua sensor tersebut dipasang paralel sedangkan data sensor 1 terhubung dengan pin analog masukkan AI 7+ dan data sensor 2 terhubung dengan pin analog masukkan AI 6+. 


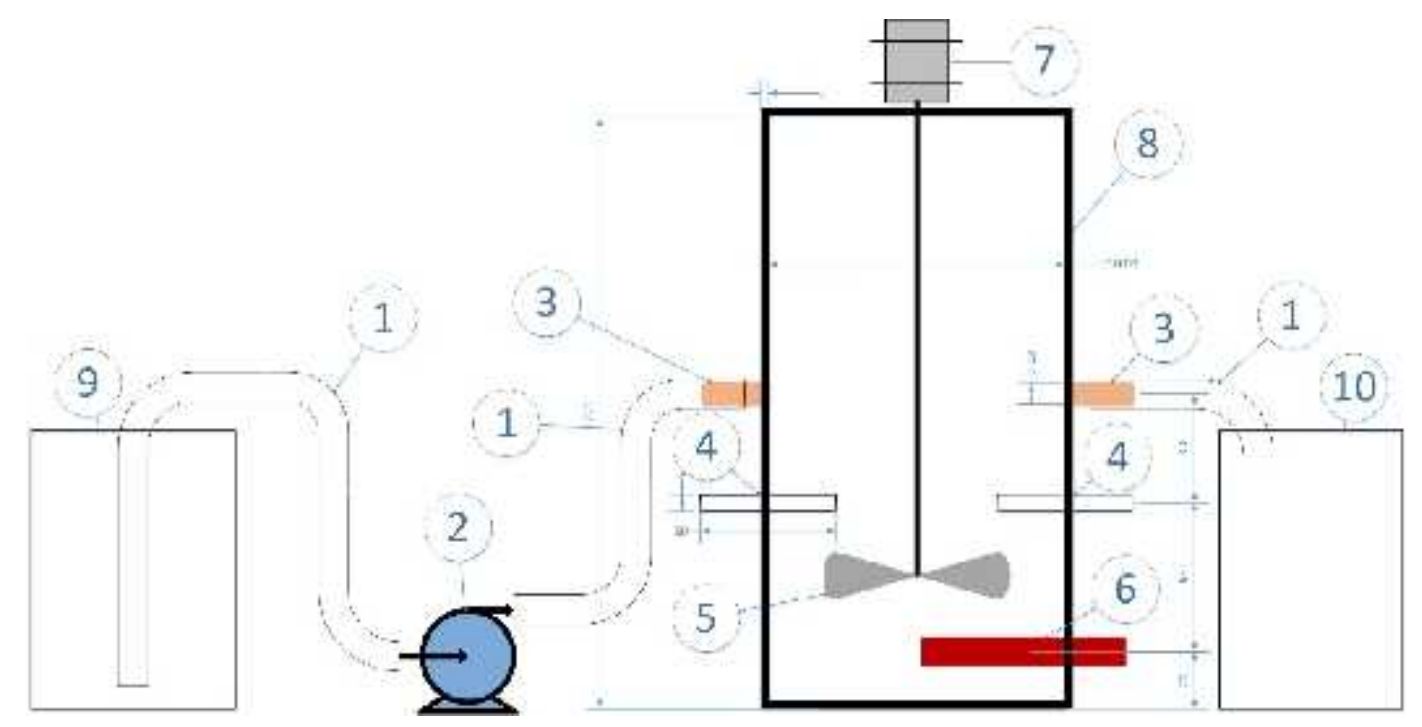

Keterangan gambar:
(1) Selang ukuran 5/16"
(2) Pompa air
(3) Hose nipple
(4) Sensor suhu
(5) Baling-baling

(6) Elemen pemanas

(7) Motor pengaduk

(8) Tangki proses

(9) Tangki air

(10) Tangki penampung

Gambar 1. Desain perancangan sistem pemanas tangki berpengaduk kontinyu

Terdapat tiga penggerak aktuator yang terhubung dengan NI ELVIS II, yaitu penggerak untuk mengendalikan elemen pemanas, penggerak untuk mengendalikan pompa air, dan penggerak untuk mengendalikan motor pengaduk. Konektor solid state relay (SSR) untuk mengendalikan elemen pemanas terdiri dari tiga pin, yaitu dua pin catu daya dan satu pin untuk sinyal kendali. Pin sinyal kendali SSR dihubungkan dengan pin analog keluaran AO0. Program akan mengirim sinyal PWM ke pin tersebut. Konektor penggerak pompa air terdiri dari 4 pin, yaitu satu pin VCC, dua pin untuk mengendalikan arah putaran, dan satu pin untuk sinyal kendali. Pin $+5 \mathrm{~V}$ dihubungkan dengan $+5 \mathrm{~V}$ NI ELVIS II. Pin IN1 dihubungkan dengan ground dan pin IN2 dihubungkan dengan $+5 \mathrm{~V}$ sehingga motor berputar berlawanan arah jarum jam. Pin EN A dihubungkan ke analog keluaran $\mathrm{AO} 1$ sebagai pin kendali pompa. Konektor penggerak motor pengaduk mempunyai cara kerja yang sama dengan konektor penggerak pompa air. Pin $+5 \mathrm{~V}$ dihubungkan dengan pin $+5 \mathrm{~V}$ NI ELVIS II. Pin IN3 dihubungkan dengan ground dan pin IN4 dihubungkan dengan $+5 \mathrm{~V}$ agar motor berputar forward. Sedangkan pin kendali motor pengaduk, yaitu EN B dihubungkan dengan pin digital keluaran DIO 1.

Tabel 1. Koneksi pin komponen dengan Pin NI ELVIS II

\begin{tabular}{|c|c|c|c|}
\hline \multirow{2}{*}{$\begin{array}{c}\text { Nama } \\
\text { Komponen }\end{array}$} & \multicolumn{2}{|c|}{ Pin yang dihubungkan } & \multirow[b]{2}{*}{ Ket. } \\
\hline & $\begin{array}{c}\text { Pin } \\
\text { komponen }\end{array}$ & $\begin{array}{l}\text { Pin NI } \\
\text { ELVIS II }\end{array}$ & \\
\hline \multirow{4}{*}{$\begin{array}{l}\text { Sensor } \\
\text { Suhu } \\
\text { LM35DZ } \\
\text { (1) }\end{array}$} & $5 \mathrm{~V}$ & $+5 \mathrm{~V}$ & \\
\hline & GND & GND & \\
\hline & DATA & AI7+ & Sinyal \\
\hline & GND & AI7- & \\
\hline \multirow{4}{*}{$\begin{array}{l}\text { Sensor } \\
\text { Suhu } \\
\text { LM35DZ } \\
\text { (2) }\end{array}$} & $5 \mathrm{~V}$ & $+5 \mathrm{~V}$ & \\
\hline & GND & GND & \\
\hline & DATA & AI6+ & Sinyal \\
\hline & GND & AI6- & \\
\hline Elemen & $\mathrm{DC}+$ & GND & \\
\hline
\end{tabular}




\begin{tabular}{|l|c|c|l|}
\hline Pemanas & DC- & GND & \\
\cline { 2 - 4 } & CH & AO0 & PWM \\
\hline \multirow{4}{*}{ Pompa air } & 5V & $+5 \mathrm{~V}$ & \\
\cline { 2 - 4 } & ENA & AO1 & PWM \\
\cline { 2 - 4 } & IN1 & GND & \\
\cline { 2 - 4 } & IN2 & $+5 \mathrm{~V}$ & \\
\hline \multirow{3}{*}{$\begin{array}{l}\text { Motor } \\
\text { pengaduk }\end{array}$} & 5V & $+5 \mathrm{~V}$ & \\
\cline { 2 - 4 } & ENB & DIO 1 & ON/OFF \\
\cline { 2 - 4 } & IN3 & GND & \\
\hline
\end{tabular}

Perancangan perangkat lunak terdiri dari dua bagian pada sistem ini yaitu, perangkat lunak pada bagian akusisi data sensor dan perangkat lunak untuk kendali aktuator. Perangkat lunak yang digunakan pada sistem ini adalah LabVIEW 2017. Diagram alir perancangan perangkat lunak pada akusisi data sensor dapat dilihat pada Gambar 2. Proses akusisi data diawali dengan pembacaan data dari sensor, kemudian masuk ke perangkat akusisi data yaitu NI ELVIS II. Nilai dari sensor berupa sinyal masukan analog, sehingga perlu diubah menjadi sinyal digital yang akan ditampilkan pada aplikasi LabVIEW sebagai sistem antarmuka.

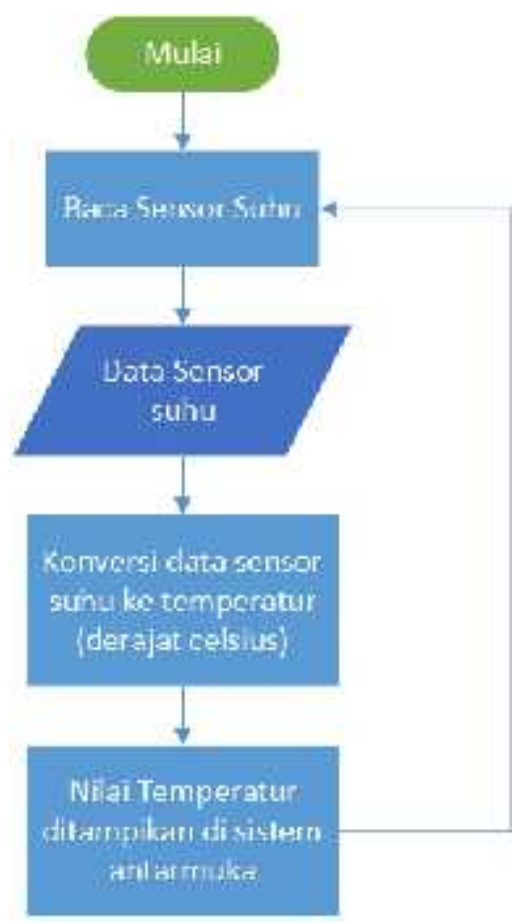

Gambar 2. Diagram alir program akusisi data sensor suhu
Diagram alir perancangan perangkat lunak untuk kendali aktuator terbagi menjadi dua mode, yaitu mode manual dan mode PID. sebelum megoperasikan sistem, langkah pertama yang dilakukan adalah memilih mode kendali pada sistem. diagram alir pemilihan mode kendali ditampilkan pada Gambar 3.

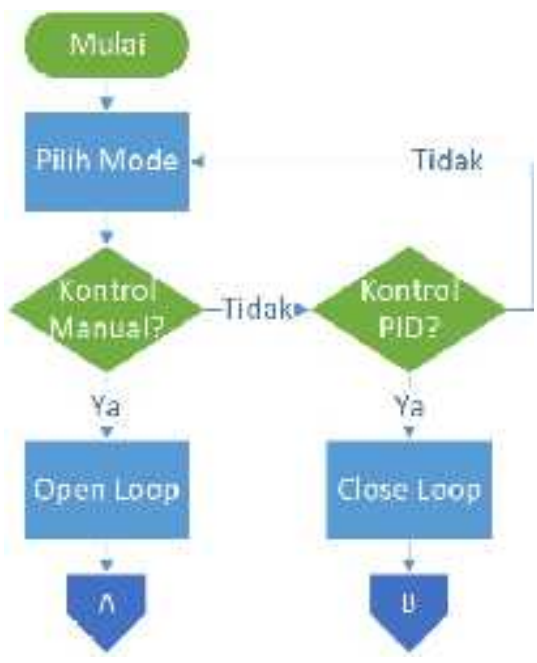

Gambar 3. Diagram alir pemilihan mode kendali sistem

Dalam diagram alir mode kendali manual, program diawal dengan memilih dioperasikan. Setelah itu, kondisi awal pompa air dalam keadaan mati/OFF. Tekan tombol pompa air untuk mengaktifkan pompa pada antarmuka. Pompa akan tetap aktif sampai tombol tersebut ditekan kembali. Sama halnya dengan pompa air, motor pengaduk mula-mula dalam keadaan mati/OFF. jika ingin mengaktifkan motor pengaduk, tekan tombol motor pengaduk dan jika ingin menonaktifkan tekan tombol kembali. Kemudian mengaktifkan elemen pemanas dilakukan dengan cara memasukkan nilai PWM pada antarmuka. Elemen pemanas akan bekerja berbanding lurus dengan nilai PWM yang dimasukkan. Diagram alir mode kendali manual ditunjukkan pada Gambar 4. 


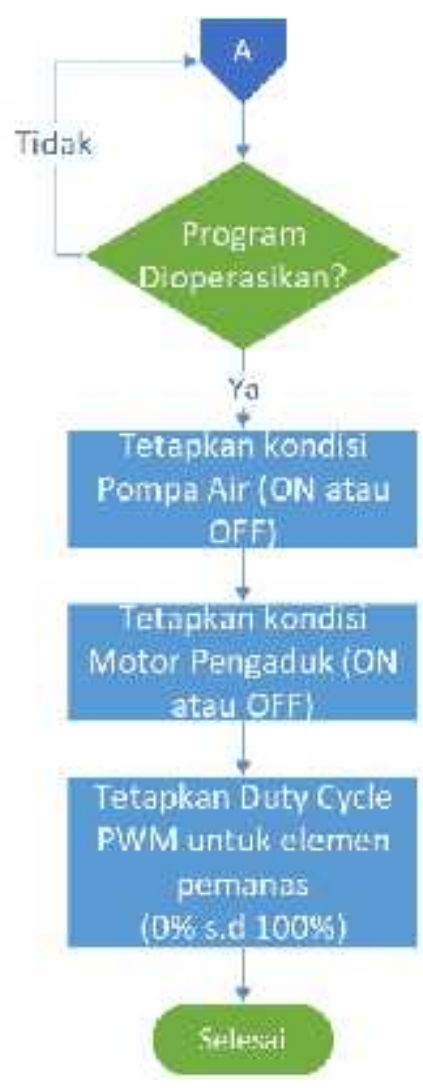

Gambar 4. Diagram alir mode kendali manual

Data titik setel suhu dan parameter PID dimasukkan terlebih dahulu, kemudian program dijalankan. Pompa air dan motor pengaduk akan aktif, kemudian antarmuka akan menampilkan nilai titik setel dan nilai suhu aktual dalam bentuk numerik dan grafik terhadap waktu. Nilai titik setel dan nilai suhu aktual dibandingkan dan diolah oleh program PID. Keluaran nilai PID diubah menjadi sinyal PWM yang akan dihubungkan dengan solid state relay (SSR). Nilai keluaran PID tersebut ditampilkan dalam antarmuka sebagai indikator kinerja aktuator yang dikendalikan. Sedangkan SSR disini akan mengendalikan tegangan yang digunakan oleh elemen pemanas. Diagram alir mode kendali manual ditunjukkan pada Gambar 5.
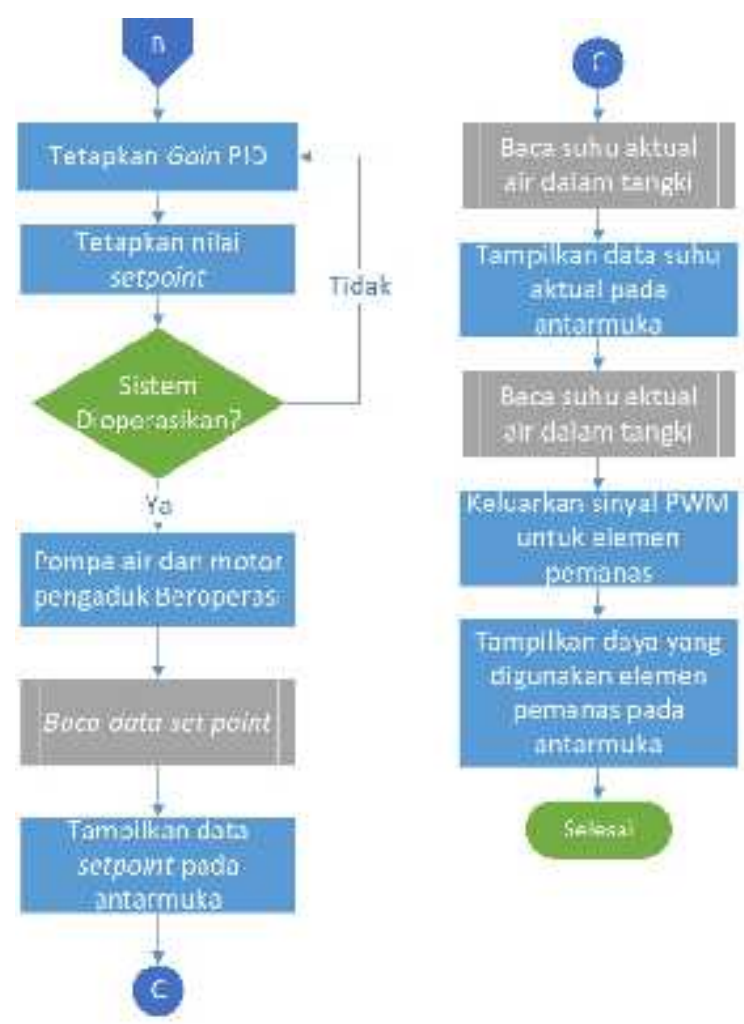

Gambar 5. Diagram alir mode kendali PID

\section{HASIL DAN PEMBAHASAN}

Pada pengujian sensor suhu LM35DZ, digunakan sebuah alat ukur tambahan yaitu termometer $\mathrm{TP}-101$ dengan ketelitian $0,1^{\circ} \mathrm{C}$ sebagai pembanding untuk mengetahui bagaimana pengaruh suhu terhadap nilai keluaran sensor. Tegangan keluaran pada sensor suhu diukur menggunakan multimeter Richmeter 102 dengan ketelitian 0,1 mV. Hasil pengujian sensor suhu ditunjukkan pada Tabel 2.

Tabel 2. Hasil pengukuran sensor Suhu

\begin{tabular}{|c|c|c|}
\hline No & $\begin{array}{c}\text { Suhu yang } \\
\text { Diuji }\left[{ }^{\circ} \mathrm{C}\right]\end{array}$ & $\begin{array}{c}\text { Tegangan Keluaran } \\
\text { Sensor }[\mathrm{mV}]\end{array}$ \\
\hline 1 & 24,9 & 255,3 \\
\hline 2 & 27,3 & 278,6 \\
\hline 3 & 30,0 & 305,0 \\
\hline 4 & 32,6 & 331,2 \\
\hline 5 & 35,2 & 356,2 \\
\hline 6 & 37,1 & 374,3 \\
\hline 7 & 39,9 & 402,3 \\
\hline 8 & 42,6 & 428,4 \\
\hline
\end{tabular}




\begin{tabular}{|c|c|c|}
\hline 9 & 45,0 & 451,7 \\
\hline 10 & 47,7 & 477,6 \\
\hline 11 & 50,0 & 500,8 \\
\hline 12 & 52,6 & 527,6 \\
\hline 13 & 55,2 & 551,8 \\
\hline 14 & 57,8 & 577,7 \\
\hline 15 & 59,9 & 599,5 \\
\hline
\end{tabular}

Pengujian dilakukan sebanyak 15 kali percobaan dengan nilai suhu yang diuji berbeda-beda. Sebagai representasi suhu air yang sebenarnya, dibuatkan grafik suhu yang diuji terhadap tegangan keluaran untuk melihat liniearitas, persamaan regresi, dan nilai koefisien determinasi (R-Square). Persamaan regresi dan nilai koefisien determinasi didapat menggunakan fungsi microsoft excel. Hubungan tersebut memiliki nilai gradien kemiringan atau gain sebesar 9,8103 $\mathrm{mV} / \mathrm{C}$ dengan nilai konstanta tambahan (c) sebesar $+10,732 \mathrm{mV}$. Hubungan tegangan keluaran terhadap suhu air memiliki hubungan yang linier terbukti dari R-Square bernilai 1 . Pembacaan tegangan keluaran rangkaian sensor tersebut kemudian dikonversi menjadi suhu yang ditampilkan di antarmuka.

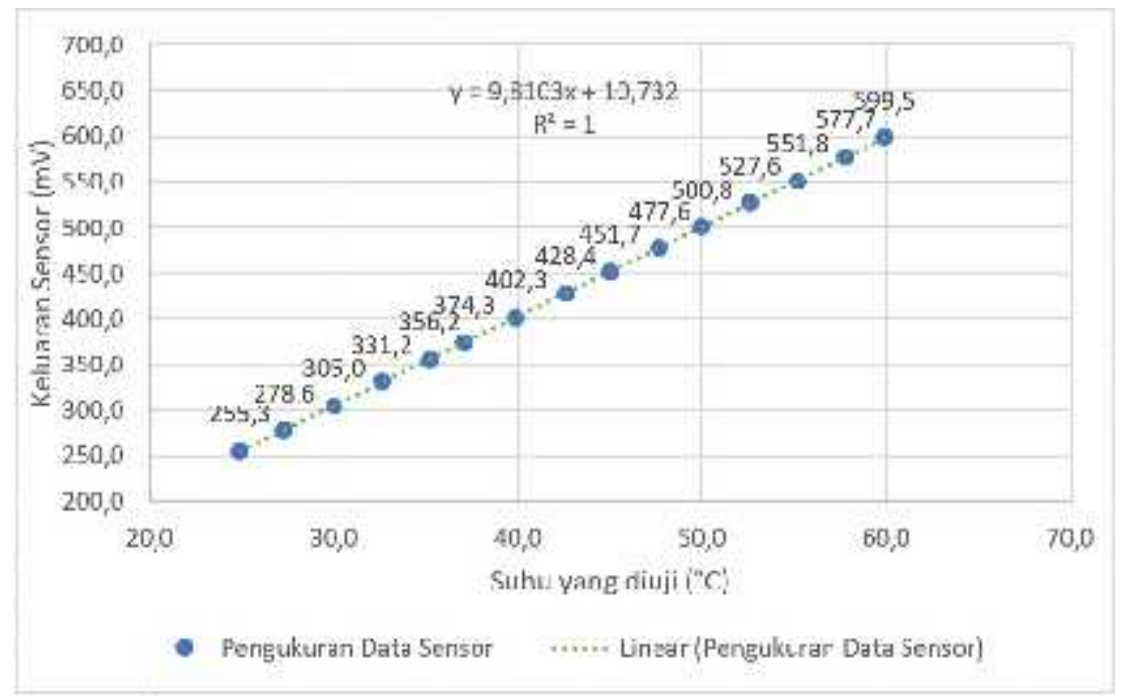

Gambar 6. Grafik tegangan keluaran sensor suhu

Pengujian karakteristik elemen pemanas bertujuan untuk mengetahui fungsi dari penggerak elemen pemanas dan menganalisis hubungan antara tegangan yang dimasukan dan daya yang digunakan oleh elemen pemanas. Pada pengujian ini, digunakan sebuah alat ukur multimeter Richmeter 102 dengan ketelitian $0,1 \mathrm{~V}$ untuk mengukur tegangan keluaran $N I$ ELVIS II yang masuk ke penggerak elemen pemanas yaitu solid state relay (SSR). Tegangan keluaran tersebut dihasilkan menggunakan persentase duty cycle pulse width modulation $(P W M)$ yang didapat diubah pada sistem antarmuka. kemudian, powermeter LACARTA digital power meter dengan ketelitian 1 Watt digunakan untuk mengukur daya operasi elemen pemanas. Hasil pengujian karakteristik elemen pemanas ditunjukkan pada Tabel 3.

Tabel 3. Data pengujian karakteristik elemen pemanas

\begin{tabular}{|c|c|c|}
\hline $\begin{array}{c}\text { Duty } \\
\text { Cycle } \\
P W M[\%]\end{array}$ & $\begin{array}{c}\text { Tegangan } \\
\text { Keluaran NI } \\
\text { ELVIS II [V DC] }\end{array}$ & $\begin{array}{c}\text { Daya Elemen } \\
\text { Pemanas } \\
\text { [Watt] }\end{array}$ \\
\hline 0 & 0,0 & 0,0 \\
\hline 10 & 0,5 & 99,0 \\
\hline 20 & 1,0 & 146,0 \\
\hline 30 & 1,5 & 196,0 \\
\hline 40 & 2,0 & 237,0 \\
\hline 50 & 2,5 & 273,0 \\
\hline 60 & 3,0 & 324,0 \\
\hline 70 & 3,5 & 342,0 \\
\hline 80 & 4,0 & 371,0 \\
\hline
\end{tabular}




\begin{tabular}{|c|c|c|}
\hline 90 & 4,5 & 405,0 \\
\hline 100 & 5,0 & 415,0 \\
\hline
\end{tabular}

Pengujian dilakukan sebanyak 10 kali percobaan dengan nilai persentase kelipatan 10 . Untuk mengetahui pengaruh nilai persentase duty cycle PWM terhadap daya elemen pemanas yang digunakan, dibuatkan grafik persentase duty cycle $P W M$ terhadap saya elemen pemanas untuk melihaat persamaan regresi dan nilai koefisien determinasi (R-Square).

Berdasarkan grafik yang ditunjukkan pada Gambar 7, pengaruh nilai persentase duty cycle $P W M$ sebagai masukkan sistem terhadap daya elemen pemanas sebagai keluaran sistem adalah polinomial. Hal tersebut terbukti dari hasil regresi polinomial dengan nilai $R$-square yang mendekati 1, yaitu 0,9916. Nilai persentase tersebut kemudian dikonversi menjadi daya elemen pemanas yang ditampilkan di antarmuka.

Pengujian karakteristik pompa air bertujuan untuk mengetahui debit air yang dialirkan pada saluran masuk oleh pompa berdasarkan variasi persentase duty cycle PWM. Pengukuran debit air dilakukan dengan mengoperasikan pompa untuk mengisi tangki yang sudah diketahui luas permukaan dan tingginya. Pompa akan beroperasi selama 10 detik yang sudah ditentukan oleh program LabVIEW untuk mengisi tangki oleh air.

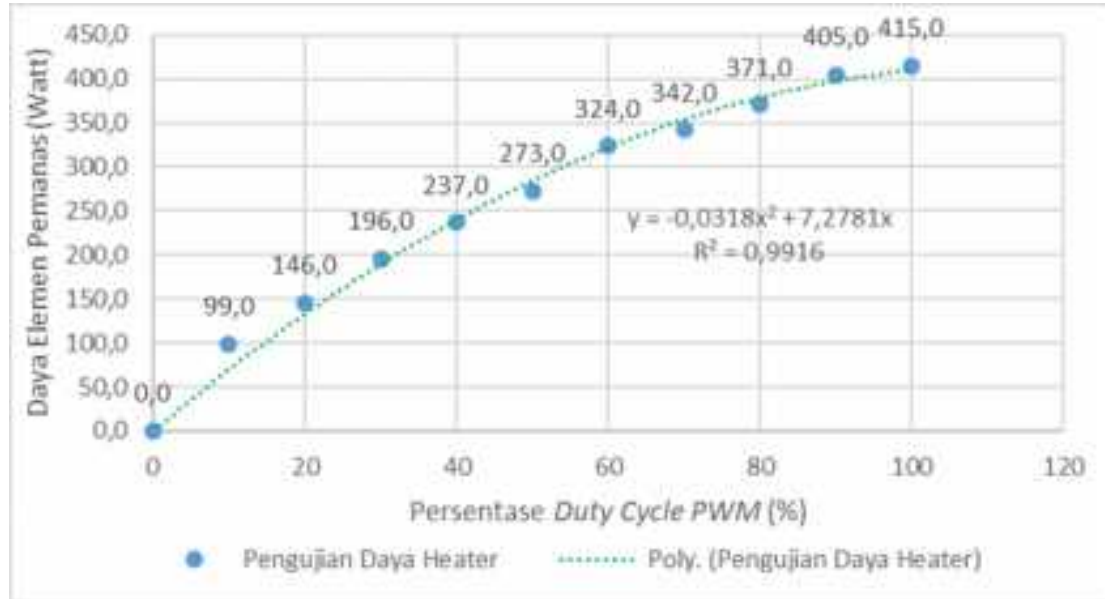

Gambar 7. Grafik hubungan persentase Duty Cycle PWM terhadap daya elemen pemanas

Setelah pompa beroperasi untuk mengisi tangki, maka diukur ketinggian permukaan air yang didapat dan dikalikan dengan luas permukaan tangki tersebut sehingga menghasilkan volume air yang dihasilkan dalam 10 detik. Untuk mengetahui debit air yang dihasilkan, maka volume air yang sudah diketahui dibagi dengan 10 sehingga didapatkan volume air dalam satu detik.

Dalam pengukuran debit air pada saluran keluar terdapat kondisi yang harus terpenuhi, yaitu tangki air sudah terisi oleh air, lubang saluran keluar diatur untuk mengisi akuarium berbentuk balok dengan luas permukaan 83,265 $\mathrm{cm}^{2}$. Kemudian, pompa dioperasikan selama 10 detik untuk mengisi tangki yang sudah terisi air, sehingga air akan mengalir ke lubang saluran keluar untuk mengisi akuarium. Tinggi permukaan air pada akuarium diukur menggunakan jangka sorong mitutoyo dengan ketelitian 0,02 mm.

Tabel 4. Data pengujian debit saluran masuk dan debit saluran keluar

\begin{tabular}{|c|c|c|}
\hline $\begin{array}{c}\text { Duty Cycle } \\
P W M[\%]\end{array}$ & $\begin{array}{c}\text { Debit Saluran } \\
\text { Masuk }\left[\mathrm{cm}^{3} / \mathrm{s}\right]\end{array}$ & $\begin{array}{c}\text { Debit Saluran } \\
\text { Keluar }\left[\mathrm{cm}^{3} / \mathrm{s}\right]\end{array}$ \\
\hline 0 & 0,0 & 0,0 \\
\hline 5 & 0,0 & 0,0 \\
\hline 10 & 0,0 & 0,0 \\
\hline 15 & 0,0 & 0,0 \\
\hline 20 & 0,0 & 0,0 \\
\hline 25 & 0,0 & 0,0 \\
\hline
\end{tabular}




\begin{tabular}{|c|c|c|}
\hline 30 & 0,0 & 0,0 \\
\hline 35 & 0,0 & 0,0 \\
\hline 40 & 0,0 & 0,0 \\
\hline 45 & 4,8 & 5,0 \\
\hline 50 & 7,6 & 8,3 \\
\hline 55 & 9,5 & 10,0 \\
\hline 60 & 12,4 & 12,5 \\
\hline 65 & 14,3 & 13,3 \\
\hline 70 & 16,2 & 15,0 \\
\hline 75 & 17,6 & 16,7 \\
\hline 80 & 19,5 & 18,3 \\
\hline 85 & 20,9 & 20,8 \\
\hline 90 & 22,8 & 22,5 \\
\hline 95 & 25,7 & 25,0 \\
\hline 100 & 29,5 & 29,1 \\
\hline
\end{tabular}

Untuk mengatur keseimbangan energi cairan dalam tangki, maka sistem harus memenuhi kondisi debit air pada saluran masuk dan saluran keluar adalah sama, dan tangki terisi oleh air. Maka dari itu, penelitian ini menggunakan nilai masukan Duty Cycle PWM $45 \%$ yang menghasilkan debit saluran masuk $4,8 \mathrm{~cm}^{3} / \mathrm{s}$ dan debit saluran keluar $5,0 \mathrm{~cm}^{3} / \mathrm{s}$.

Pengujian motor pengaduk dilakukan untuk mengetahui pengaruh motor pengaduk terhadap perubahan suhu air dalam tangki dan waktu yang dibutuhkan sistem untuk menaikkan suhu. Skenario pengujian dilakukan dengan menaikkan suhu ruangan yaitu $25,9^{\circ} \mathrm{C}$ menjadi suhu titik setel $40^{\circ} \mathrm{C}$, parameter PID yang digunakan adalah $\mathrm{Kp}=100, \mathrm{Ti}=0,01$, $\mathrm{Td}=0$, dan debit air yang masuk dan keluar 4,8 $\mathrm{cm}^{3} / \mathrm{s}$. Berikut tabel hasil pengujian proses pemanasan mengoperasikan motor pengaduk dan tanpa motor pengaduk.

Tabel 5. Data pengujian proses pemanasan tanpa mengoperasikan dan mengoperasikan motor pengaduk

\begin{tabular}{|l|c|c|c|c|c|c|c|}
\hline \multirow{2}{*}{ Pengujian } & \multicolumn{3}{|c|}{ Suhu Awal $\left({ }^{\circ} \mathrm{C}\right)$} & \multicolumn{3}{c|}{ Suhu Akhir $\left({ }^{\circ} \mathrm{C}\right)$} & $\begin{array}{c}\text { Waktu } \\
\text { penyelesaian } \\
\text { [Ts] (s) }\end{array}$ \\
\cline { 2 - 7 } & Sensor 1 & Sensor 2 & Rata-rata & Sensor 1 & Sensor 2 & Rata-rata & 346 \\
\hline $\begin{array}{l}\text { Tanpa } \\
\text { Mengoperasikan } \\
\text { Motor Pengaduk }\end{array}$ & 25,9 & 25,9 & 25,9 & 40,3 & 39,3 & 39,8 & 360 \\
\hline $\begin{array}{l}\text { Mengoperasikan } \\
\text { Motor Pengaduk }\end{array}$ & 25,9 & 25,9 & 25,9 & 39,8 & 39,8 & 39,8 & 360 \\
\hline
\end{tabular}

Berdasarkan Tabel 5, proses pemanasan tanpa menggunakan pengaduk mendapatkan perbedaan suhu yang dideteksi oleh sensor 1 dan sensor 2. Selisih hasil pembacaan dari kedua sensor tersebut adalah $1^{\circ} \mathrm{C}$. Maka dari itu, proses pemanasan tanpa mengoperasikan motor pengaduk menyebabkan suhu dalam tangki tidak homogen. Proses pemanasan dengan mengoperasikan motor pengaduk menghasilkan suhu air yang homogen. Suhu yang dideteksi oleh sensor 1 dan sensor 2 bernilai sama yaitu $39,8^{\circ} \mathrm{C}$. Meskipun waktu yang dibutuhkan untuk mencapai titik setel lebih lama dibanding dengan tanpa mengoperasikan motor pengaduk, proses pemanasan menggunakan motor pengaduk

sudah memenuhi persyaratan sistem yang dibuat.

Hasil rancang bangun GUI (graphical user interface) sistem kendali pemanas tangki berpengaduk kontinyu dapat dilihat pada Gambar 8. Sedangkan Gambar 9 menampilkan proses pengendalian suhu air dalam tangki menggunakan pengendali PID. Penyajian data antarmuka GUI ini dibuat secara interaktif karena sistem dapat memberikan reaksi terhadap aksi yang diberikan oleh pengguna. Sistem antarmuka kendali suhu menyajikan hasil pembacaan sensor secara riil setiap 0,1 detik, sehingga pengguna dapat menyaksikan perubahan sistem secara langsung. 


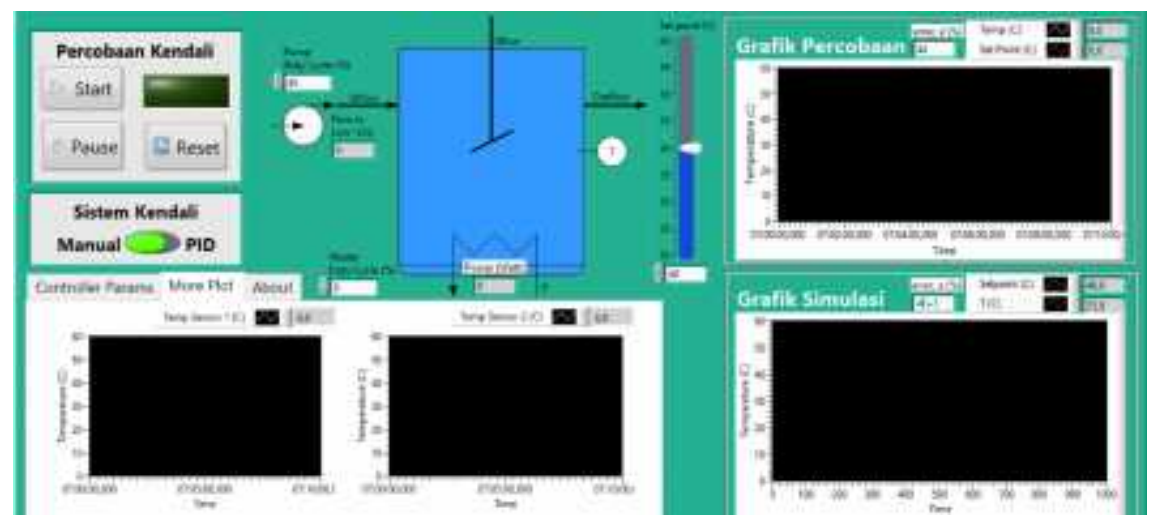

Gambar 8. Hasil perancangan GUI

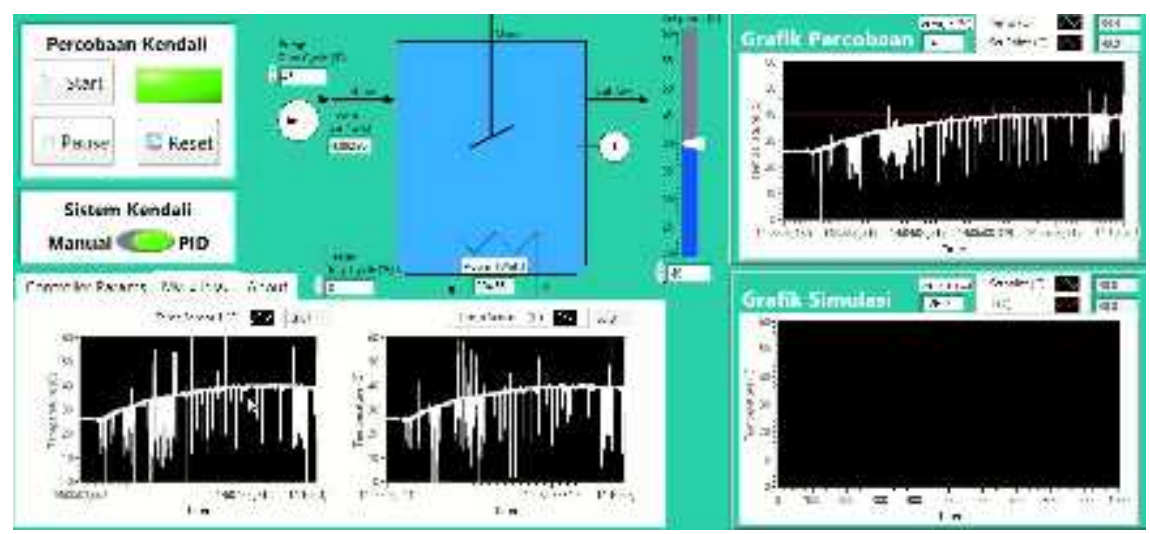

Gambar 9. GUI sistem kendali suhu pemanas tangki berpengaduk kontinyu

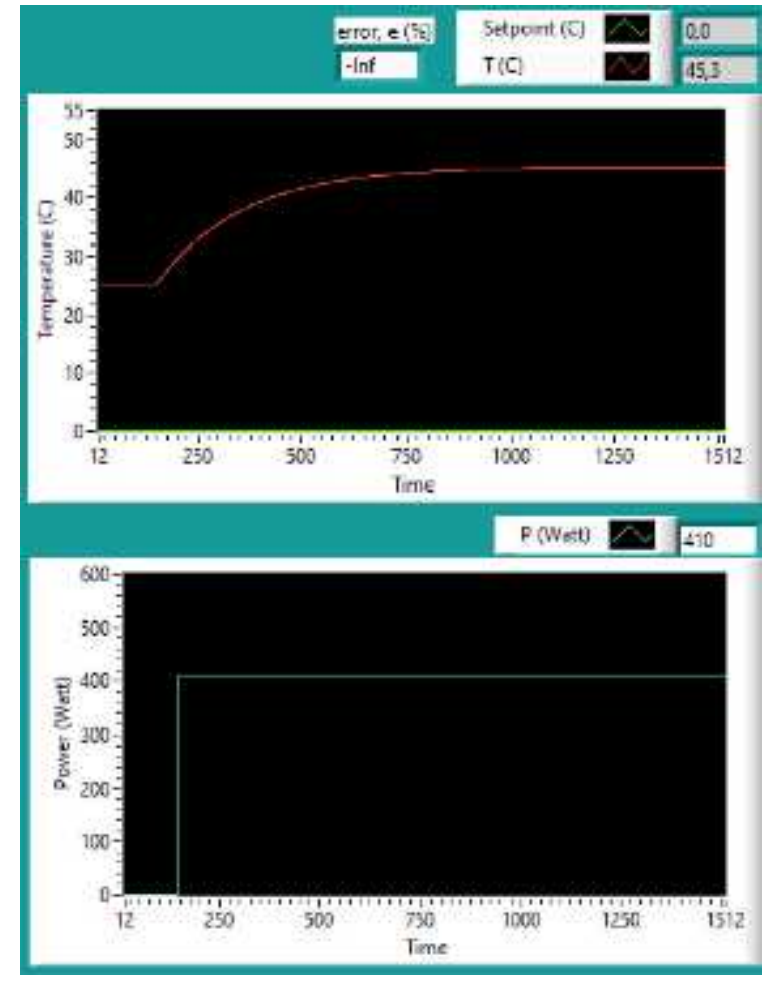

Gambar 10. Masukan Step-Respone Step Plant pemanas tangki berpengaduk kontinyu
Proses penalaan pengendali PID menerapkan metode Ziegler-Nichols orde pertama, karena keluaran sistem bernilai konstan ketika diberi masukkan konstan. Langkah pertama yang dilakukan adalah melihat respon sistem pada sistem lingkar terbuka. Parameter sistem yang digunakan yaitu suhu awal dan suhu air yang masuk ke sistem adalah $25^{\circ} \mathrm{C}$, debit air yang masuk dan keluar $4,8 \mathrm{~cm}^{3} / \mathrm{s}$ dan kemampuan elemen pemanas $100 \%$.

Dalam menentukan nilai konstanta waktu tunda (L) dan konstanta waktu (T) dari grafik respon yang dihasilkan oleh sistem, dibuat gambar garis singgung pada titik belok kurva berbentuk $\mathrm{S}$ dan menentukan perpotongan garis singgung antara garis dengan sumbu waktu dan sumbu variabel process (garis tangensial) (Ogata, 2010).

Berdasarkan gambar 11, nilai konstanta waktu tunda (L) yang didapatkan sebesar 3 detik, sedangkan nilai konstanta waktu (T) sebesar 208 detik. kedua nilai tersebut 
digunakan untuk menentukan nilai parameter PID pada sistem berdasarkan tabel peraturan Ziegler-Nichols orde pertama. Nilai parameter PID yang sudah didapatkan berdasarkan perhitungan, digunakan pada sistem dan berikut hasilnya respon sistem lingkar tertutup.

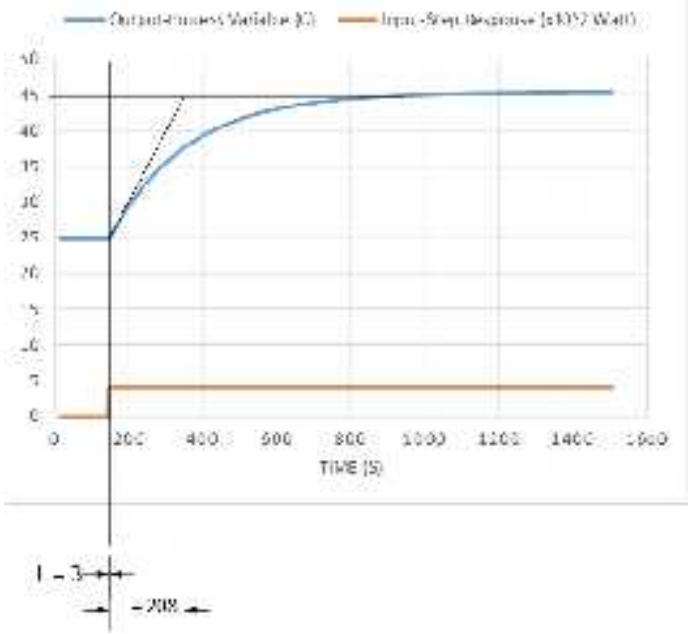

Gambar 11. Kurva respon plant pemanas tangki berpengaduk kontinyu

$$
\begin{gathered}
\kappa p=\frac{T}{L} \\
\kappa p=1.2 \approx \frac{209}{3} \\
\kappa p=83.2 \\
T i=2 * L \\
T i=Z * 3 \\
T i=6 \\
T d=0.5 \approx L \\
T d=0.5 * 3 \\
T d=1.5
\end{gathered}
$$

Melihat hasil respon sistem dengan parameter PID yang sudah didapat, maka perlu dilakukan penalaan ulang parameter PID agar sistem mencapai titik setel yang diinginkan dengan kecepatan dan akurasi yang tinggi. setelah dilakukan penalaan ulang parameter PID, maka didapat parameter PID yang sesuai kebutuhan sistem untuk mencapai titik setel yang diinginkan, yaitu $\mathrm{Kp}=83.2, \mathrm{Ti}=0.03$,
$\mathrm{Td}=0.00$. Respon grafik hasil penalaan ulang parameter PID ditunjukkan pada gambar 13.

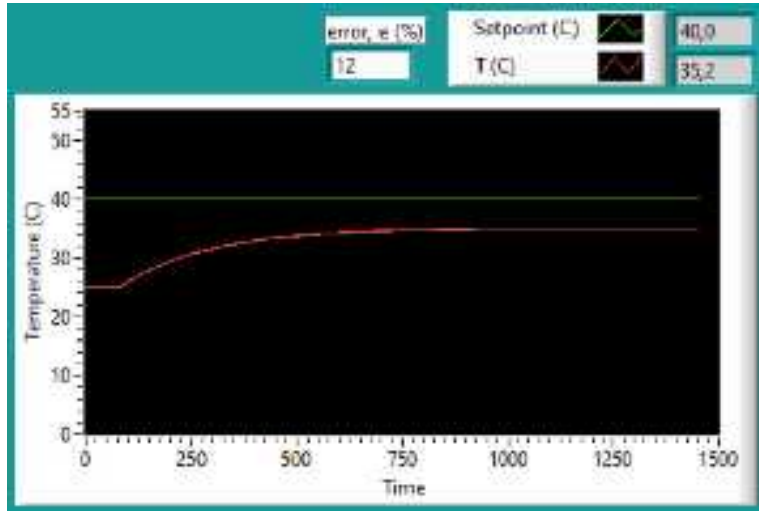

Gambar 12. Respon grafik dengan parameter PID Kp=83.20 Ti=6.00 $\mathrm{Td}=1.50$

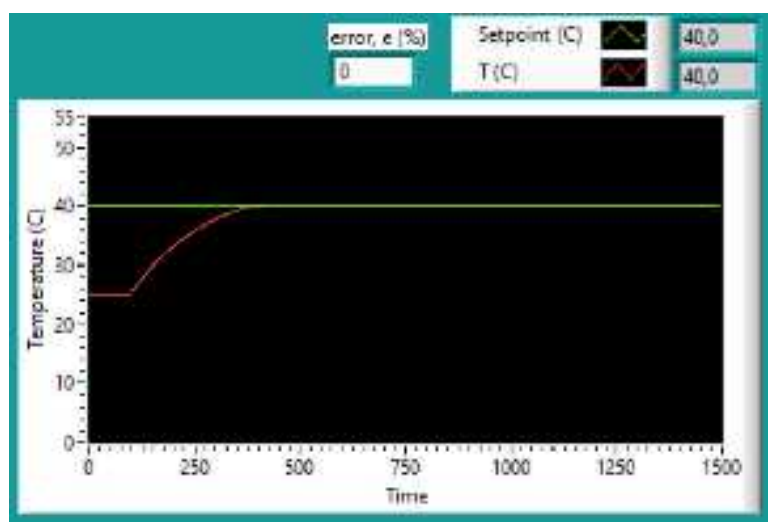

Gambar 13. Respon grafik dengan parameter PID Kp=83.20 Ti=0.03 $\mathrm{Td}=0.00$

\section{SIMPULAN}

Konstruksi sistem pada model pemanas tangki berpengaduk kontinyu telah dibuat dapat menampung air sebanyak $1000 \mathrm{~mL}$. Berdasarkan hasil percobaan dan analisis yang telah dilakukan, pengendali PID konvensional dapat diimplementasikan pada penelitian ini karena mampu melakukan pengendalian suhu air dalam tangki sesuai dengan titik setel yang diinginkan. Metode penalaan pengendali PID menerapkan aturan penalaan Ziegler-Nichols metode pertama serta penalaan manual. Hasil penalaan parameter PID sesuai kebutuhan sistem untuk mencapai titik setel yang diinginkan, yaitu $\mathrm{Kp}=83.2, \mathrm{Ti}=0.03, \mathrm{Td}=0.00$. 
Pengembangan pada sistem kendali suhu pemanas tangki berpengaduk kontinyu dapat ditingkatkan lagi pembacaan sensor suhu LM35D agar terhindar dari gangguan atau noise, sehingga data yang ditampikan pada sistem antarmuka lebih akurat. Selain itu, sistem ini dapat ditambahkan gangguan atau disturbance agar performa sistem dengan menerapkan pengendali PID konvensional dapat duji. Membandingkan penerapan jenis pengendali PID konvensional dengan jenis pengendali yang lain untuk melihat jenis pengendali mana yang menghasilkan performa sistem lebih baik.

\section{DAFTAR RUJUKAN}

Jayachitra, A., \& Vinodha, R. (2014). Genetic Algorithm Based PID Controller Tuning Approach for Continuous Stirred Tank Reactor. Advances in Artificial Intelligence, $\quad 2014, \quad 1-8$. https://doi.org/10.1155/2014/791230

Jibril, M., Tadese, M., \& Tadese, E. A. (2020). Temperature Control of Stirred Tank Heater using Optimal Control Technique. June, https://doi.org/10.20944/preprints202006. 0285.v1

Kabila, V., \& Glan Devadhas, G. (2015). Comparative Analysis of PID and Fuzzy PID Controller Performance for Continuous Stirred Tank Heater. Indian Journal of Science and Technology, 8(23). https://doi.org/10.17485/ijst/2015/v8i23/8 5351

Ogata, K. (2010). Modern Control Engineering. In M. J. Horton (Ed.), Indian Pediatrics (Fifth, Vol. 39, Issue 12). Pretince Hall.

Rajagopalen, A. S. (2013). Identification of an Effective Controller for a Stirred Tank Heater Process. International Journal of Engineering and Advanced Technology, 3(1), 271-279.

Septiani, N. I., Bayusari, I., Caroline, C., Haiyunnisa, T., \& Suprapto, B. Y. (2017). Optimization of PID control parameters with genetic algorithm plus fuzzy logic in stirred tank heater temperature control process. ICECOS 2017 - Proceeding of 2017 International Conference on Electrical Engineering and Computer Science: Sustaining the Cultural Heritage Toward the Smart Environment for Better Future, August, 61-66. https://doi.org/10.1109/ICECOS.2017.816 7167

Yudho Suprapto, B., Bayusari, I., Caroline, \& Muhammad. (2018). Comparison of Cascade and Feedforward-Feedback Controllers for Temperature Control on Stirred Tank Heater Systems. Proceedings - 2018 International Seminar on Application for Technology of Information and Communication: Creative Technology for Human Life, ISemantic 2018, September 2018, 166-170. https://doi.org/10.1109/ISEMANTIC.2018 .8549782 